\title{
Most significant barriers and proposed solutions for medical schools to facilitate simulation-based undergraduate curriculum in OBGYN
}

\author{
Hira Salman ${ }^{1}$ (D) \\ ๑) Springer-Verlag GmbH Germany, part of Springer Nature 2021
}

\begin{abstract}
Despite having a good understanding of medicine, doctors lack clinical skills, problem-solving abilities, and the ability to apply knowledge to patient care, particularly in unanticipated circumstances. To overcome this, medical education has evolved into a system-oriented core curriculum with cognitive, psychomotor, and affective learning goals. With an emphasis on problem-based learning, the educator's aim is to establish a long-term, predetermined improvement in the learner's behavior, acquired skills, and attitudes (Datta R, Upadhyay KK, Jaideep CN. Simulation and its role in medical education. Med J Armed Forces India. 2012;68(2):167-172. https://doi.org/10.1016/S0377-1237(12)60040-9). However, teaching these disciplines to real patients is almost impossible; this is where simulation comes in. This opinion paper will discuss the relevance and necessity of a simulation-based undergraduate curriculum in obstetrics and gynecology. What are the biggest obstacles that medical schools face in making the most of simulation-based learning, and how can they be overcome?
\end{abstract}

Keywords OBGYN · Simulation-based curriculum · Undergraduates · Medical schools · Simulation · Clinical skills · Strategies $\cdot$ Challenges $\cdot$ Fidelity $\cdot$ COVID-19

\section{Introduction}

One of the most fundamental strategies in this era to teach crisis resource management skills to promote the professional development of frontliners is introducing the simulation-based medical curriculum, which will provide comprehensive and realistic training and safer patient care in several ways. It is a process, not a technology, for promoting experiential and reflective learning, intending to instill the proper mindset and skills to cope competently with reallife sensitive situations in a planned and prescribed manner while respecting patients' moral and legal rights [1].

To prevent any potential breach of patient privacy, students must not involve directly in any patient care; however, there is a need to attend an orientation before beginning clinical practice. The simulation model assists medical students in gaining clinical experience and understanding the progression and clinical manifestations of diseases in specific patients. Simulation allows students to gain valuable

Hira Salman

drhirasalman@gmail.com; 2448968@dundee.ac.uk

1 University of Dundee, Dundee, Scotland experience in areas where resources are scarce but technological skills are essential. Effective simulator models are available for teaching shoulder dystocia, vaginal breech delivery, obstetric emergencies, operative hysteroscopy, and laparoscopy [12].

What are the challenges medical schools facing to integrate simulation-based learning for undergraduates? Furthermore, what are the potential options for overcoming such obstacles?

One of the most important roadblocks is the expense of implementing simulation-based medical education. A well-conducted economic evaluation can assist stakeholders such as program directors, regulators, and curriculum designers determine the best use of resources when choosing the simulation modality or assessment method. For example, a great deal of practice is necessary for procedural competencies as we do not want medical students to improve this ability with patients in the early training stages. So, we can use everything from citrus fruits to board games to hand-crafted corduroy and neoprene versions of vaginal cuffs. These low-fidelity simulation models do not include artificial intelligence; nevertheless, they allow students to practice throwing nodes before entering the operating room [13]. In specific training scenarios, 
hybrid simulation, which involves using a patient actor in conjunction with a task-trainer during the same session, may be as effective as high-fidelity simulators while also providing superior training contexts to enhance patient learners' relationships with caregivers and better immerse trainees in the feelings and emotions of the scenario. There is evidence that a hybrid-birthing simulator enables quick maneuvers for handling a shoulder dystocia delivery and is beneficial for non-technical skills like communication and team training [16]. High-fidelity modeling recreates a scenario to replace actual patient encounters with a supervised clinical practice that mimics significant aspects of the real world in a completely immersive approach. Highfidelity birthing simulators are ideal for teaching both natural and assisted vaginal deliveries.

To conclude, the potential option for getting over the expense roadblock is to carefully evaluate which type of fidelity simulation model is suitable for optimal patient safety outcomes by the clinical simulationist because money invested in the medical industry directly affects patient lives. Task coaches, scenario manikins, or human patient simulators of full-fidelity may achieve various goals, depending on the desired outcome. Economic assessment in medical education research is still in its early stages. However, there is much room for the state-of-the-art application of these methods in this field [9]. If you are looking for a more detailed breakdown, try "Comprehensive simulation in healthcare: operations, technology, and innovative practice" written by Scott B. Crawford, MD, FACEP, CHSOS, the Director for Simulation at TTUHSC El Paso, is a practical guide to help practitioners prepare for a wide range of simulations in healthcare. The book starts with an introduction to the simulation of healthcare, including staff, curricula, and space. Eight core areas of knowledge/skill discuss the fundamental aspects of healthcare simulation technology specialist in the following chapters. Finally, it addresses the advantages of establishing a relationship with business partners and provides best practices and innovations.

The second most difficult challenge in simulation-based education is maintaining an SP Program. As per William Osler, "For the junior student in medicine and surgery, it is a safe rule to have no teaching without a patient for a text, and the best teaching is that taught by the patient himself." Simulated patients trained in a structured manner are known as low-technology resources, but running this program is costly as their compensation rate is $\$ 20.00$ per hour [14]. However, SP's professional input is the secret to the success of the simulation-based training, and they have a high level of realism and potential for teaching general and specialized communication skills. So, it is best to utilize standardized patients in training scenarios where peer role-play is inappropriate, such as breaking bad news or providing a trainee assessment alternative.
The emerging trend of using simulation as a teaching method for assessing and preparing students is reflected in medical schools and their curricula as they are responsible for designing the curriculum and ensuring that adequate educational facilities are available to shape the futures of today's undergraduates-tomorrow's physicians. In order to facilitate both outcomes-based and competency-based medical education, there is a need to develop a simulationbased procedural skills curriculum and this could be one of the difficulties encountered in the simulation-based medical education of OBGYN undergraduates. To make this obstacle easier to overcome a non-profit, membership-based organizations with the ultimate aim of delivering optimal health care to women like APGO for women's health educators are now offering contemporary, applicable educational resources for physician-educators and learning strategies for faculty, students, and residents. The Undergraduate Medical Education Committee (UMEC) of the Association of Professors of Gynecology and Obstetrics (APGO) provides educators with an overview of the use of simulation in undergraduate medical education in the field of obstetrics and gynecology in the "To the Point" series and the APGO Medical Student Educational objectives, 11th edition, provides a succinct overview of the goals and objectives of a complete Obstetrics and Gynecology clinical program. Members of the UMEC are responsible for assisting APGO in achieving its mission and objectives; the primary responsibilities of this committee are to provide consultation service to departments concerning undergraduate medical education programs and establish, build, and evaluate a variety of teaching and learning [2].

Faculty expertise and competencies in debriefing and simulator logistics are critical components of successful SBME delivery. Several studies have shown that debriefing preparation workshops are a feasible and effective method of faculty training. Debriefing experience can be gained by completing simulation instructor training courses provided by various simulation programs, attending seminars, at conferences, and pursuing fellowship training or advanced degrees in simulation [4].

In situ simulation drills during clinical ward postings are among the most successful ways to introduce simulationbased education for undergraduates as sitting and listening to lectures does not allow for significant activation, which is the essential learning and memory retention element. Simulation involves the team, but it also allows them to practice in a more supervised environment. An in-situ simulation is much more rewarding than an off-site simulation, which means simulation occurs in the actual clinical environment. This method helps the learners to learn technical skills, teamwork, and communication in a real-world setting. It enables the detection of possible facility problems and obstacles to treatment which, of course, is challenging to gain in a simulation lab or other off-site locations. By this, we not 
only enhance communication and coordination between doctors and midwives by including training at the undergraduate level, as well as break down professional barriers before they develop. This is especially important in low-middle-income countries with high rates of maternal and perinatal mortality and a deeply ingrained hierarchical healthcare system [6]. Obstetrics is a team-based, high-risk specialty with a high level of litigation. Failures in teamwork lead to poor outcomes for mothers and babies; therefore, effective multiprofessional teamwork is important. Furthermore, obstetric team simulation preparation shows healthy neonatal outcomes after obstetric complications. Simulation training is increasingly being used for undergraduate training because it helps students to consolidate their learning and apply their expertise and experience in practice [3]. Simulation for obstetric emergencies is a relatively recent area of interest, but it increases patient safety and outcomes. It is becoming an essential component of both education and patient care. The Council on Patient Safety in Women's Health Care has released "Practicing for Patients: In-Situ Simulation Program Manual", whose main agenda is that if all members of the labor and delivery team practice and simulate medical emergencies on their actual labor and delivery unit, they will reduce obstetric related morbidity and mortality by improving the team's communication and response in a medical emergency [11].

\section{How to promote simulation-based medical education in the COVID-19? Being ready for post-pandemic transformation}

Above all obstacles, one of the most significant challenges that the entire world faced during the COVID 19 pandemic was on the educational system. Computerized simulation education products are in high demand for healthcare training environments, which eventually necessitate vast infrastructures. Significant obstacles to using virtual simulation in clinical education started from clinical simulation training operating systems, system architecture technology, encrypted data, cloud-based eLearning, and a professional technical team. Therefore, investing in simulation-based instructional management technologies and resources to keep clinical education and competency training on track during the pandemic is an expeditious need today [15]. The use of digital technologies for educational purposes, such as virtual, mixed, and augmented reality, are likely to be the most significant aspects of the transformative and post-COVID medical education [5]. A possible solution for quickly adapting to these new technologies is to develop courses for teachers and lecturers on how to prepare courses for AR/VR and a structure that allows teachers to adapt their material for AR/VR quickly [10]. Not only advance simulation, but according to one study, OBGYN students, residents, and fellows who lack hands-on experience due to the COVID-19 pandemic benefit from the use of homemade simulator models as well [7].

One of the authors stressed the importance of reopening simulation labs and facilities by following simple and doable strategies like establishing a COVID-19 response task force, using space, establishing access conditions to the simulation facility, personal hygiene measures, use of protective devices, physical distancing, management during training activities, personnel management, cleaning/ disinfection, and review of emergency plans/procedures. The mentioned are realistic focus points with operational tips and mitigation advice to prepare the reader to reopen SF after the lockdown safely. So plan the future event with protection and versatility in mind [8]. In addition to this, including medical students in the healthcare simulation center's staff is one way to support undergraduate simulation-based medical teaching [17].

\section{Conclusion}

According to the points raised, it is clear that there are many opportunities for facilities to integrate simulationbased curriculum, especially for OBGYN undergraduates including: the appropriate use of resources like low, hybrid, and high fidelity simulators; the use of contemporary simulation models like VR/AR and MR for teaching basic medical sciences; utilization of standardized patients programs in training scenarios where the alternate strategy is not possible; by designing evidence of curriculum documentation; the strategy of curriculum review with the help of APGO Medical Student Educational Objectives Guide; overcoming the barrier of simulation training by running workshops to train faculty; effective use of in situ simulation drill and last but not the least be innovative and ready to adapt to changes during the pandemic situation and have sound knowledge and urge to get the latest updates in simulation technology. However, there are still some gray areas with room for improvement and much scope for researchers to assess how best to incorporate simulators in a more primary phase of medical education.

Funding This study is supported by University of Dundee.

\section{Declarations}

Conflict of interest I have no conflicts of interest to disclose. 


\section{References}

1. Al-Elq A (2010) Simulation-based medical teaching and learning. J Fam Community Med 17(1):35. https://doi.org/10.4103/13191683.68787

2. Association of Professors of Gynecology \& Obstetrics-APGO (2020) APGO undergraduate medical education committee (UMEC). https://apgo.org/page/umec. Accessed 21 May 2021

3. Carpenter C, Rowlands S (2019) P60 'Filling the gap': a simulation course for fourth year medical students to enhance understanding of obstetric emergencies. BMJ Simul Technol Enhanc Learn 5(Suppl 2):A87.2-A88. https://doi.org/10.1136/bmjstel2019-aspihconf.161

4. Cheng A, Grant V, Dieckmann P, Arora S, Robinson T, Eppich W (2015) Faculty development for simulation programs: five issues for the future of debriefing training. Simul Healthc 10(4):217222. https://doi.org/10.1097/SIH.0000000000000090

5. Gaur U, Majumder MAA, Sa B, Sarkar S, Williams A, Singh K (2020) Challenges and opportunities of preclinical medical education: COVID-19 crisis and beyond. SN Compr Clin Med 2(11):1992-1997. https://doi.org/10.1007/s42399-020-00528-1

6. Gorantla S, Bansal U, Singh JV, Dwivedi AD, Malhotra A, Kumar A (2019) Introduction of an undergraduate interprofessional simulation based skills training program in obstetrics and gynaecology in India. Adv Simul 4(1):1-9. https://doi.org/10. 1186/s41077-019-0096-7

7. Hoopes S, Pham T, Lindo FM, Antosh DD (2020) Home surgical skill training resources for obstetrics and gynecology trainees during a pandemic. Obstet Gynecol 136(1):56-64. https://doi.org/ 10.1097/AOG.0000000000003931

8. Ingrassia PL, Capogna G, Diaz-Navarro C, Szyld D, Tomola S, Leon-Castelao E (2020) COVID-19 crisis, safe reopening of simulation centres and the new normal: food for thought. Adv Simul. https://doi.org/10.1186/s41077-020-00131-3

9. Lin Y, Cheng A, Hecker K, Grant V, Currie GR (2018) Implementing economic evaluation in simulation-based medical education: challenges and opportunities. Med Educ 52(2):150-160. https://doi.org/10.1111/medu.13411
10. Nesenbergs K, Abolins V, Ormanis J, Mednis A (2020) Use of augmented and virtual reality in remote higher education: a systematic umbrella review. Educ Sci. https://doi.org/10.3390/educs ci11010008

11. American College of Obstetricians and Gynecologists (2021) Obstetric In-Situ Drill Program Manual. Council on patient safety in women's healthcare. Retrieved from https://safehealth careforeverywoman.org/wp-content/uploads/Practicing-for-Patie nts-In-Situ-Simulation-Manual_General-V2-3.2021.pdf. Accessed 21 May 2021

12. Ren HY, Sun ZJ, Zhu L, Lang JH, Pan H, Wu X (2017) Curriculum using simulation models to teach gynecology and obstetrics to trainees. Chin Med J 130(8):997-1000. https://doi.org/10.4103/ 0366-6999.204116

13. Higgins E, King C, Reed V (2020) Simulation in obstetrics and gynecology education-consult QD. https://consultqd.clevelandc linic.org/simulation-in-obstetrics-and-gynecology-education. Accessed 21 May 2021

14. Standardized Patient Program (2020) Texas Tech University Health Sciences Center. https://www.ttuhsc.edu/simulation/sp. aspx. Accessed 21 May 2021

15. Tabatabai S (2020) Simulations and virtual learning supporting clinical education during the covid 19 pandemic. Adv Med Educ Pract 11:513-516. https://doi.org/10.2147/AMEP.S257750

16. Deering $S$ (2018) Using simulation technology to reduce maternal morbidity. https://www.contemporaryobgyn.net/view/using-simul ation-technology-improve-maternal-morbidity. Accessed 18 May 2021

17. Viggers S, Østergaard D, Dieckmann P (2020) How to include medical students in your healthcare simulation centre workforce. Adv Simul 5(1):1-6. https://doi.org/10.1186/s41077-019-0117-6

Publisher's Note Springer Nature remains neutral with regard to jurisdictional claims in published maps and institutional affiliations. 